\title{
Avaliação do efeito da condutividade na eletro-coagulação-flotação aplicada ao tratamento físico-químico de águas residuárias
}

\author{
Condutivity effect in electro-coagulation-flotation applied to \\ physico-chemical wastewater treatment.
}

\author{
Mário Luiz Rodrigues Focoํㅜ Francisco Javier Cuba Terán²
}

\begin{abstract}
Resumo
Este trabalho estudou o efeito da condutividade na aplicação simultânea dos princípios da eletrólise da água, da coagulação química e da flotação no tratamento de águas residuárias com elevado teor de matéria em suspensão, como forma de caracterizar a eletro-coagulação-flotação (ECF). Apresentamse resultados dos experimentos realizados na instalação piloto implantada e operada no Laboratório de Controle Ambiental, no campus da Unicamp em Limeira. A ECF se desenvolveu em um reator eletrolítico, onde a água passa por eletrodos de alumínio conectados a uma fonte de potencial. As reações eletroquímicas promoveram a emissão de íons $\mathrm{Al}^{3+}$ a partir do ânodo, neutralizando as forças repulsivas dos poluentes, formando flocos. No cátodo ocorreu evolução de micro bolhas de hidrogênio que carregam os flocos para o topo da solução, concretizando a flotação e remoção do contaminante. O sistema foi monitorado visando encontrar condições ótimas de operação em termos de tempo de residência do líquido no reator, influência da adição de $\mathrm{NaCl}$ para aumentar a condutividade do afluente e influência da inversão da polaridade sobre a passivação catódica. Em testes realizados com águas residuárias do processo de lavagem de automóveis, verificou-se eficiência de remoção de cor em torno de $86,14 \%$, de turbidez $90,15 \%$ e de óleos e graxas de $85,43 \%$.

Palavras-chave: Eletro-coagulação-flotação. Tratamento água residuária. Coagulação química.
\end{abstract}

\begin{abstract}
This study reports on the effect of conductivity on the simultaneous applicability of water electrolysis, chemical coagulation and flotation fundamentals in the treatment of wastewater with large amounts of suspended matter, characterizing electro-coagulation-flotation (ECF) . Results from experiments carried out in a pilot study implanted and operated in the Laboratory of Environment Control (LCA), at the State University of Campinas in Limeira are presented. ECF was developed in an electrolytic reactor where water passed through aluminum electrodes connected to a power supply. Electrochemical reactions promoted $\mathrm{Al}^{3+}$ ions emission from anode, neutralizing repulsive pollutant forces, forming flakes. An evolution of micro hydrogen bubbles occurred, carrying the flakes to the top of the solution, causing flotation and polluter removal. System monitoring aimed at reaching optimal operation conditions regarding time of liquid permanence in the reactor, influence of the $\mathrm{NaCl}$ addition on the increase of affluent conductivity, and influence of polarity inversion over cathodic passivation. Results from carwash wastewater treatment reported $86 \%$ efficiency rate for color, $90,15 \%$ for turbidity and $85,43 \%$ for oil and axle-grease removal.
\end{abstract}

Key words: Electro-coagulation-floatation. Wastewater treatment. Chemical coagulation. 


\section{Introdução}

Grande parte dos estabelecimentos industriais tem enfrentado crescentes problemas quanto ao lançamento de seus efluentes. Como em muitos casos a descarga na rede pública de esgotos não é possível, pode ocorrer o descarte no sistema de águas pluviais, o que certamente não é recomendável.

Há a necessidade da aplicação de um tipo de tecnologia atualizada adequada à realidade do país, para tornar a sua aplicação viável às pequenas empresas produtoras de cargas poluidoras de material em suspensão. Por isso, é um grande desafio aprimorar técnicas de tratamento de água residuária em estabelecimentos de pequeno porte, que diminuam os riscos de contaminação e ao mesmo tempo privilegiar um baixo custo de implantação e operação. (TEIXEIRA, 2003).

Dentre os vários processos, podem-se mencionar os tratamentos físicos, que são caracterizados por métodos de separação de fases: sedimentação, decantação, filtração, centrifugação ou flotação dos resíduos. Esses métodos correspondem à transferência dos resíduos para uma nova fase. (BERNARDO, 1993).

Além dos métodos físicos, existem ainda processos por troca iônica, oxidação química, biológica e adsortivos. Novas tecnologias também vêm sendo muito estudadas, entre elas, os processos oxidativos avançados (POA's) e as unidades de osmose reversa. (CRESPILHO; SANTANA; REZENDE, 2004).

A coagulação seguida de sedimentação consiste na remoção dos sólidos presentes no efluente por meio da separação das fases sólida e liquida, ficando a fase sólida (impurezas presentes no efluente) depositada na parte inferior dos decantadores ao passo que a fase líquida (sobrenadante) é retirada da unidade pela parte superior.

Na coagulação seguida de flotação, ocorre uma inversão quanto à separação das fases, sendo as impurezas (fase sólida flotada) removidas do tanque de flotação pela parte superior. A seleção do método é realizada em função das características do efluente. Fatores operacionais como tempo de retenção, natureza do efluente, temperatura e tamanho de partículas devem ser considerados. (CRESPILHO; REZENDE, 2004).

Noprocesso de eletro-coagulação-flotação(ECF), pequenas partículas e outros poluentes podem ser desestabilizados por íons $\mathrm{Al}^{3+}$ produzidos a partir dos ânodos e em seguida removidos por flotação com gás hidrogênio gerado a partir dos cátodos, na eletrólise. A duração do processo de flotação é marcantemente mais curta comparada ao de sedimentação depois da coagulação. (HU et al. 2005).

A suspensão (resíduo flotado) pode ser removida por processos físicos convencionais (raspagem, sucção etc.).

Atualmente, pesquisas estão sendo realizadas investindo em tratamentos que envolvem reatores eletroquímicos na descontaminação de efluentes contendo óleos e graxas, e elevada carga de sólidos em suspensão.

Vik et al. (1984), em sua avaliação da eletrocoagulação para tratamento de água potável, demonstraram que mesmo produzindo água tratada de qualidade similar, a quantidade de íons do coagulante requeridos e o lodo formado com eletrocoagulação eram muito menores do que se verifica com a coagulação convencional.

\section{Métodos}

O reator de eletro-coagulação-flotação é constituído de um sistema bipolar com celas em paralelo, contendo 6 eletrodos de alumínio, 2 de alimentação (chamados de placas condutoras) e 4 de sacrifício (colocados sem interconexão elétrica entre as placas condutoras), e essa configuração recebeu o nome de colméia. Os eletrodos foram ligados em uma fonte do tipo conversor $\mathrm{CA} / \mathrm{CC}$ da marca Instrutherm modelo FA 1030.

Recalcou-se o efluente bruto (EB) para o reator a partir do reservatório de armazenamento com 
auxílio de uma bomba dosadora, e manteve-se vazão constante. Após a passagem do efluente através dos eletrodos, pode-se notar a formação dos flocos e a elevação dos mesmos por meio de microbolhas. Posteriormente ocorreu a separação entre a água clarificada e o lodo, em separador construído em PVC e implantado na parte superior da unidade conforme se pode notar na Figura 1. A água clarificada era armazenada em outro reservatório de forma a permitir a coleta de amostras para caracterização do efluente.

O lodo retido no separador foi retirado manualmente por meio de raspagem.

O monitoramento do desempenho do sistema foi realizado a partir da caracterização da água residuária bruta e do efluente tratado, de forma a verificar sua qualidade em relação aos seguintes parâmetros: turbidez, pH, concentração de óleos e graxas, cor e sólidos totais.

$\mathrm{O}$ afluente bruto era proveniente de um lavador de carros próximo ao campus, coletado com homogeneização prévia, de forma que ele se tornasse representativo do despejo gerado.

Visando otimizar o desempenho, foi promovido o aumento de condutividade por meio da adição de $\mathrm{NaCl}$ e com a mesma finalidade foram variados outros parâmetros hidrodinâmicos do sistema piloto.

As determinações de óleos e graxas, sólidos totais e outras análises foram realizadas de acordo com os procedimentos do "Standart Methods for The Examination of Water and Wastewater" 19a. edição (1990).

A condutividade do efluente foi estudada, com o objetivo de verificar o efeito do acréscimo de $\mathrm{NaCl}$, no aumento da eficiência do sistema.

A inversão da polaridade foi realizada a cada 2 minutos, visando minimizar os efeitos da passivação catódica.

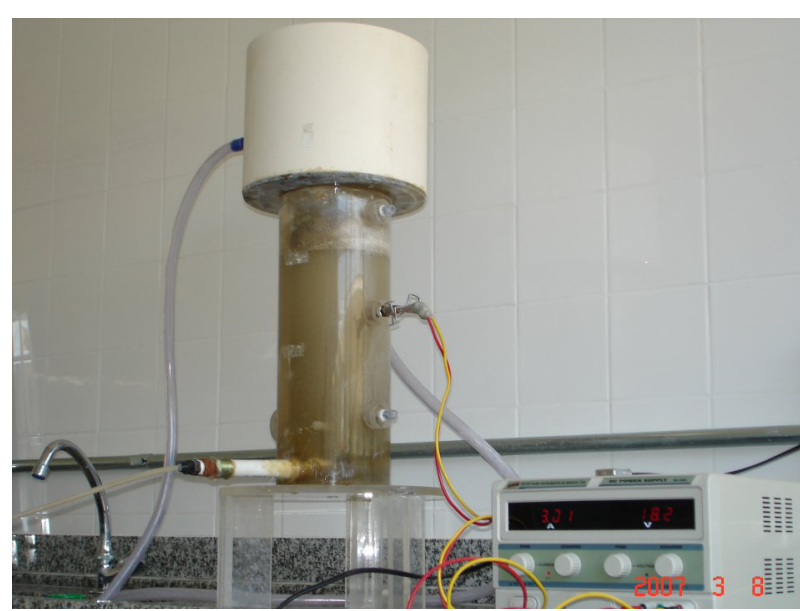

Figura 1. Fotografia do sistema constituído pelo reator e fonte de energia

\section{Resultados e discussão}

Alguns parâmetros foram fixados, tendo em vista resultados obtidos em trabalhos de otimização do sistema. A Tabela 1 mostra os parâmetros fixados para eletro-coagulação-flotação (ECF).

Tabela 1. Parâmetros fixados para ECF

\begin{tabular}{ll}
\hline Parâmetros & \\
\hline temperatura do efluente bruto $\left({ }^{\circ} \mathrm{C}\right)$ & 25,0 \\
volume reator $(\mathrm{L})$ & 10,0 \\
tempo de detenção (min) & 66,0 \\
vazão $\left(\mathrm{L} \cdot \mathrm{h}^{-1}\right)$ & 8,75 \\
\hline
\end{tabular}

Devido à capacidade limitada do equipamento utilizado como fonte de potencial externo em termos de fornecimento de corrente elétrica e ao afluente apresentar baixa condutividade, fezse necessário adicionar $\mathrm{NaCl}$ ao líquido para aumentar a condutividade, e, conseqüentemente, permitir passagem de corrente elétrica com maior intensidade.

$\mathrm{Na}$ Tabela 2, é possível verificar que o acréscimo de $\mathrm{NaCl}$ ao líquido implicou um aumento da condutividade e intensidade de corrente no mesmo. 
Tabela 2. Aumento da condutividade e da corrente a partir do acréscimo de $\mathrm{NaCl}$

\begin{tabular}{cccc}
\hline $\begin{array}{c}\text { Etapas } \\
\text { Tratamento }\end{array}$ & $\begin{array}{c}\mathrm{NaCl} \\
(\mathrm{g} / \mathrm{L})\end{array}$ & $\begin{array}{c}\text { Condutividade } \\
\left(\mathrm{mS} / \mathrm{cm}^{2}\right)\end{array}$ & $\begin{array}{c}\mathrm{I} \\
(\mathrm{A})\end{array}$ \\
\hline EB & --- & 2,32 & --- \\
ET 1 & --- & 2,32 & 1,61 \\
ET 2 & 5,0 & 8,18 & 3,15 \\
ET 3 & 7,5 & 12,54 & 5,50 \\
\hline
\end{tabular}

EB - efluente bruto, ET - efluente tratado

Para cada amostra, as análises e determinações eram realizadas em triplicata (tempo de detenção de 66,0 min) obtendo-se 3 resultados para cada parâmetro.

Em função da condutividade do afluente, foram definidas três etapas, as mesmas que foram denominadas como: ET-1, ET-2 e ET-3, conforme Tabela 2.

No primeiro experimento, manteve-se a fonte de potencial externo em sua capacidade máxima, ou seja, a tensão em $33,0 \mathrm{~V}$, permitindo que a corrente desenvolvida variasse entre 0 e $10 \mathrm{~A}$.

A corrente varia em função da condutividade do meio onde se encontram os eletrodos. Assim, mantendo a tensão fixa em seu valor máximo, o acréscimo de $\mathrm{NaCl}$ proporcionava um aumento de corrente máximo, em tais condições.

Dessa forma, cada etapa do tratamento, caracterizada pelo aumento da concentração de $\mathrm{NaCl}$ (com o aparelho operando em sua capacidade máxima), foi caracterizada pelo incremento da corrente máxima atingida, procedimento que permitiu estabelecer a concentração ótima de $\mathrm{NaCl}$.

Inicialmente, a corrente e tensão ótimas foram encontradas em função da remoção de cor e turbidez. $\mathrm{Na}$ etapa ET-1 com densidade de corrente de 1,61 A e tensão fixa de $33,0 \mathrm{~V}$, encontraram-se valores de $22,96 \%$ e $37,20 \%$ na remoção de cor e turbidez respectivamente; na ET-2, com intensidade de corrente de 3,15 A, as respectivas remoções foram de $89,4 \%$ e $89,58 \%$, e finalmente na ET-3, com intensidade de corrente 5,5 A, a remoção de cor foi de $93,0 \%$ e de turbidez foi $96,0 \%$, conforme apresentado na Figura 2.

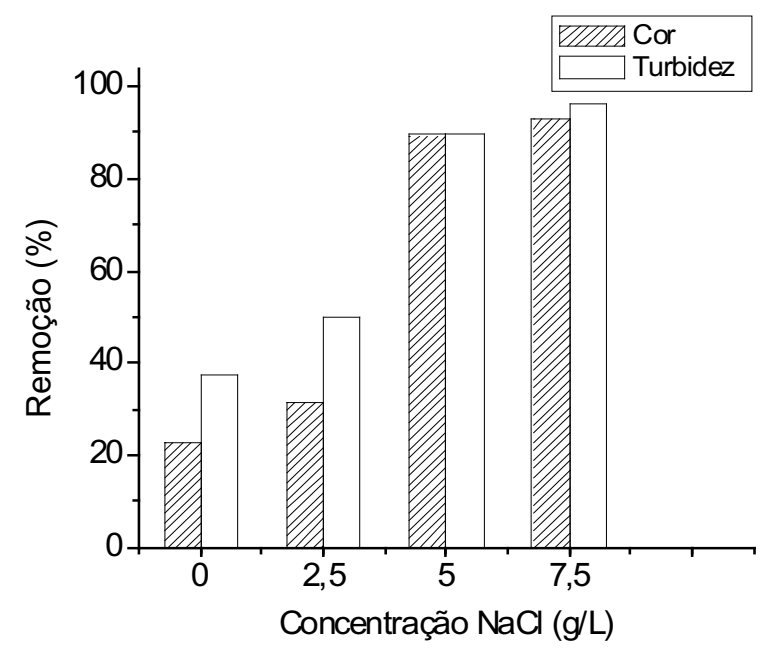

Figura 2. Variação da remoção de cor e turbidez em função da concentração de $\mathrm{NaCl}$ aplicada.

Pela observação da Figura 3, é possível verificar o aspecto visual do efluente ao longo do processo de Eletro-coagulação-flotação.

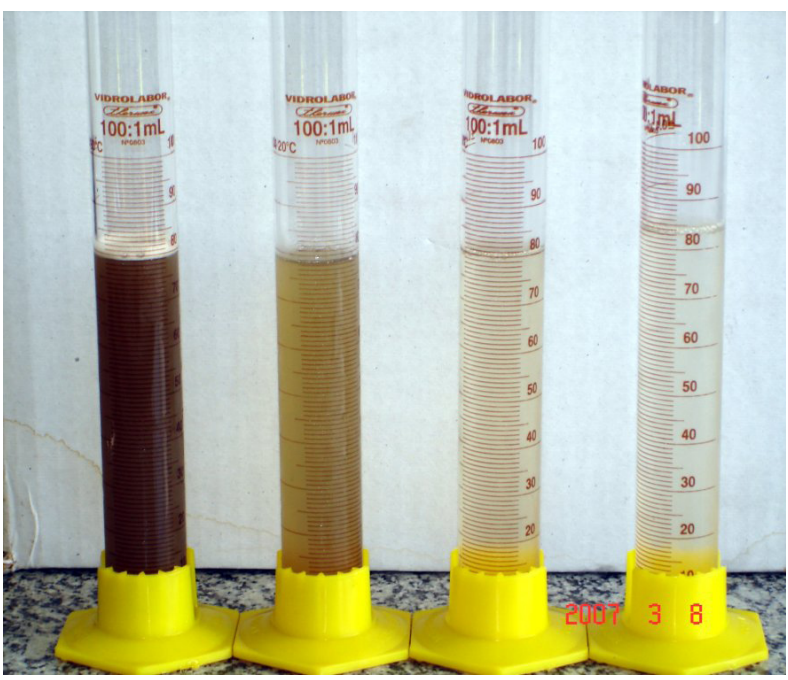

Figura 3. Aspecto visual das etapas do tratamento variando desde o afluente bruto (primeiro da esquerda) até o efluente tratado.

Os valores referentes ao primeiro experimento foram encontrados sem a inversão de polaridade, porém a passivação nos eletrodos foi grande e, após uma semana de operação, já durante a realização do segundo experimento, a diminuição da eficiência decorrente da queda excessiva da condução de 
corrente nos eletrodos diminuiu a ponto de ser necessária à lavagem dos mesmos em solução de ácido muriático.

É possível observar, na Figura 4, que ocorreu um decaimento na remoção de cor e turbidez no segundo experimento (E02) e que, após a lavagem dos eletrodos e a inversão da polaridade ocorre um aumento na eficiência de remoção, verificado nas curvas (E03).

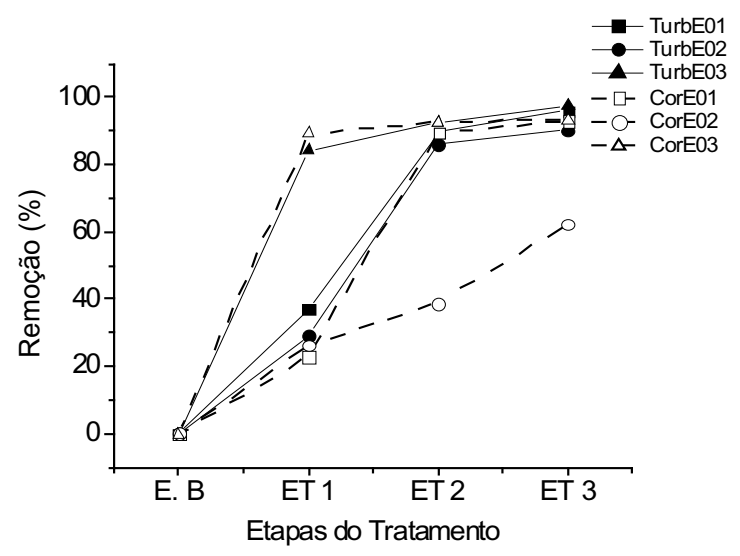

Figura 4. Influência da inversão da polaridade na ECF

Segundo Crespilho, Santana e Rezende (2004), a fim de evitar a passivação dos eletrodos, faz-se necessária à inversão da polaridade. Tal inversão diminui a passivação, aumentando a vida útil do eletrodo até três vezes, e ao, mesmo tempo, diminui a resistividade do sistema.

No segundo experimento utilizou-se a mesma metodologia do primeiro, realizando-se inversão da polaridade a cada dois minutos. Assim, para ET-1 com condutividade do efluente bruto de 2,35 $\mathrm{mS} / \mathrm{cm} 2$, densidade de corrente com inversão de polaridade de $0,75 \mathrm{~A}$ e tensão de $33,4 \mathrm{~V}$, a remoção de cor ficou em 26,38 \% e turbidez em 29,40\%. $\mathrm{Na}$ ET-2, com densidade de corrente de 3,50 A, as respectivas remoções são de $38,93 . \%$ e $86,14 \%$ e finalmente na ET-3 com densidade de corrente de 5,50 A e tensão de $22,0 \mathrm{~V}$, remoção de cor de 62,34 $\%$ e de turbidez de $90,15 \%$.
O aumento da condutividade provoca uma rápida diminuição da voltagem entre os eletrodos, e conseqüentemente diminuição da energia requerida. Muitos pesquisadores recorrem à adição de $\mathrm{NaCl}$, para variar a condutividade do afluente, e, conseqüentemente otimizar o consumo de energia, porém Chen, Chen e Yue (2000), cita que tal aplicação tem pouca influencia no desempenho da remoção de poluentes.

No presente trabalho, verificou-se que o aumento da condutividade com auxílio de $\mathrm{NaCl}$ permite realizar a dimuição da voltagem aplicada, porém ocorre um aumento significativo dos SDT (sólidos dissolvidos totais) nas etapas em que houve o acréscimo de $\mathrm{NaCl}$. Esse acréscimo é verificado por meio do cotejo dos dados com a remoção de SST (sólidos suspensos totais) na etapa em que não houve acréscimo de cloreto de sódio. Isso significa que no segundo experimento ocorre um aumento de $201,47 \%$ de SDT com acréscimo de 7,5 g/L de $\mathrm{NaCl}$ e remoção de $23,68 \%$ de SST. Já na etapa em que não há adição de $\mathrm{NaCl}$, ocorre redução de 13,31 $\%$ de SDT e remoção de SST igual a 43,42\%. Nesse caso, a diferença é $19,74 \%$ a mais na remoção de SST sem adição de $\mathrm{NaCl}$, enquanto no primeiro experimento a diferença remoção de SST é 47,53\% maior, com aumento de $302,48 \%$ de SDT no efluente tratado 3, conforme é mostrado na Figura 5.

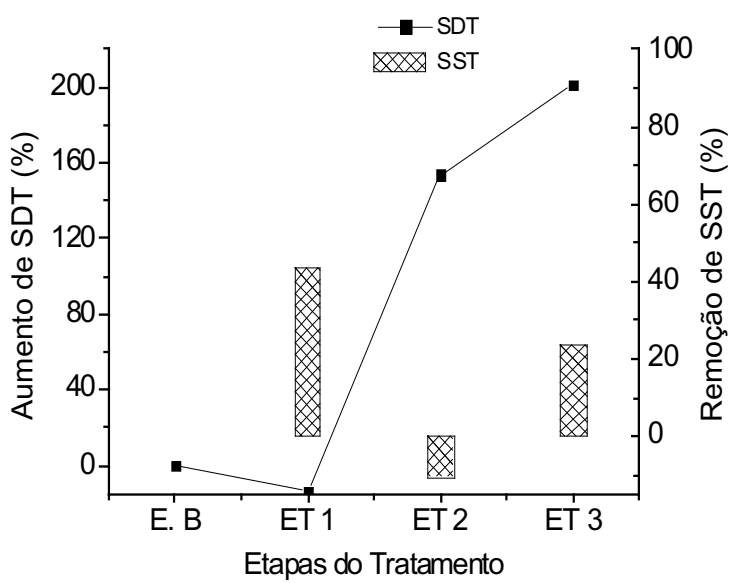

Figura 5. Eficiência de remoção de sólidos suspensos totais e aumento sólidos dissolvidos totais. 
O aumento esperado na concentração de sólidos totais, decorrente da adição de $\mathrm{NaCl}$, é mostrado na Figura 5 para cada etapa do tratamento, e existe inclusive remoção de $13,32 \%$ no ponto ET 1 . No mesmo gráfico, estão apresentadas as eficiências de remoção de sólidos suspensos totais, mostrando no ponto ET 2 um aumento de 10,52 \%, possivelmente em decorrência de problemas decorrentes da separação da fase sólida (lodo flotado) no reator.

Segundo Chen, Chen e Yue (2000), uma das maiores vantagens da Eletroflotação é a remoção de óleos e graxas. Esse fato, segundo o pesquisador, ocorre devido à facilidade de coagulação e flotação das moléculas de óleos e graxas, como conseqüência da interação dessas moléculas com o hidróxido de alumínio, formando colóides com densidade bem menor que a da água. E em seu estudo na separação de poluentes de água residuária de restaurante por eletrocoagulação, obtiveram-se 99,9 \% na remoção de óleos e graxas.

A remoção de óleos e graxas neste trabalho foi verificada no primeiro experimento em $83,69 \%$ de remoção na etapa ECF2 e, no segundo experimento em ECF3, em 85,43\%. Os valores médios são mostrados na Figura 6.

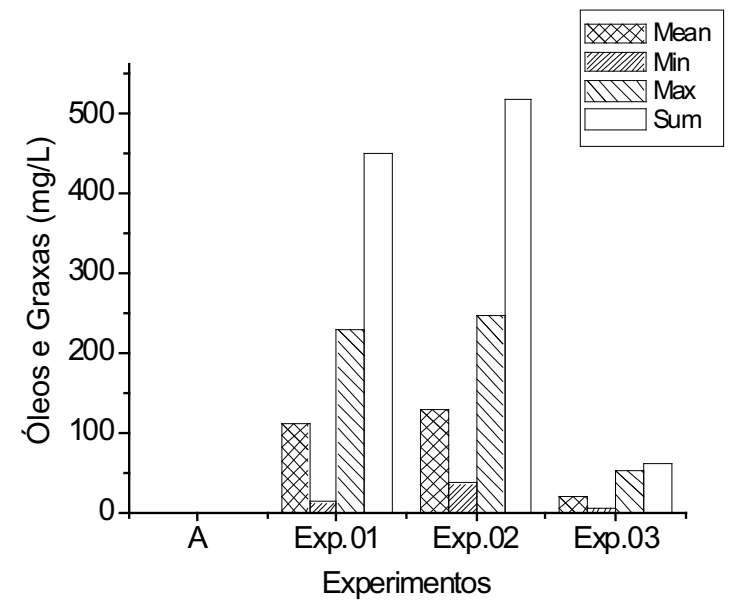

O ensaio dos cones de IMHOFF, após o tratamento, resultou no ponto EB do primeiro experimento em 1,00 ml/L em ECF3 49,0 ml/L, no segundo experimento em EB, $1,50 \mathrm{ml} / \mathrm{L}$ e ECF3 $68,0 \mathrm{ml} / \mathrm{L}$.

\section{Conclusões}

Verificou-se que o aumento da condutividade com auxílio de $\mathrm{NaCl}$ permite a diminuição da voltagem aplicada, porém ocorre um aumento significativo dos SDT se comparado com a remoção de SST na etapa em que não há adição do mesmo.

Os processos distintos de eletro-coagulação e eletroflotação são eficientes, segundo verificado em trabalhos da bibliografia, porém são sempre associados a outras unidades de separação de fases do efluente. No presente trabalho, a eficiência na remoção de poluentes tais como cor, turbidez, óleos e graxas é significativa, embora existam ainda problemas na unidade de separação, fato verificado por meio do ensaio de sólidos sedimentáveis o qual aponta a grande quantidade de material sedimentado.

É necessária a inversão da polaridade, a fim de evitar a passivação dos eletrodos, e conseqüente perda de potência do reator.

\section{Agradecimentos}

Os autores do presente trabalho agradecem ao FAEPEX Fundo de Apoio ao Ensino, à Pesquisa e à ExtensãodaUnicampe aoCNPq-Conselho Nacional de Desenvolvimento Científico e Tecnológico, pelo apoio concedido ao desenvolvimento da pesquisa em questão.

Figura 6. Quantidade de óleos e graxas 


\section{Referências}

BERNARDO, L. D. Métodos e técnicas de tratamento de água. Rio de Janeiro: ABES, 1993.

CHEN, X.; CHEN, G., YUE, P. L. Separation of pollutants from restaurant wastewater by electrocoagulation. Separation and Purification Technology, New York, v. 19, n. 1-2, p. 65-76, 2000.

CRESPILHO, F. N.; SANTANA, C.G.;REZENDE, M. O. O. Tratamento de efluente da indústria de processamento de coco utilizando eletroflotação. Química Nova, São Paulo, v. 27, n. 1, p. 2-5, 2004.

CRESPILHO, F. N.; REZENDE, M. O. O. Eletroflotação: princípios e aplicações. São Carlos: Rima, 2004.
HU, C. Y., LO, S.L., LI, C. M., KUAN, W. H. Treating chemical mechanical polishing (CMP) wastewater by electro-coagulation-flotation process with surfactant. Journal of Hazardous Materials, Amsterdam, v. 120, n. 1, p. 15-20. 2005.

TEIXEIRA, P. C. Emprego da flotação por ar dissolvido no tratamento de efluentes da lavagem de veículos visando a reciclagem da água. 2003. Dissertação. (Mestrado em Engenharia Civil) - Universidade Estadual de Campinas, Campinas.

VIK, E. A.; CARLSON, D. A.; EIKUM, A. S.; GJESSING, E. T. Electrocoagulation of potable water. Water Research, New York, v. 18, n. 11, p. 1355-1360, 1984. 
